\title{
Serum microRNA miR-206 is decreased in hyperthyroidism and mediates thyroid hormone regulation of lipid metabolism in HepG2 human hepatoblastoma cells
}

\author{
YINGJUAN ZHENG ${ }^{1,2 *}$, CHAO ZHAO $^{3 *}$, NAIJIAN ZHANG ${ }^{3}$, WENQIN KANG $^{1}$, RONGRONG LU ${ }^{1}$, \\ HUADONG WU ${ }^{3}$, YINGXUE GENG ${ }^{1}$, YAPING ZHAO ${ }^{2,3}$ and XIAOYAN XU ${ }^{1,2}$ \\ ${ }^{1}$ Department of Pediatrics, Shu Yang Union Medical College Hospital, Suqian, Jiangsu 223600; \\ ${ }^{2}$ Department of Postgraduates, BengBu Medical College, Bengbu, Anhui 233004; ${ }^{3}$ Department of Clinical Laboratory, \\ The 82nd Hospital of Chinese People's Liberation Army, Huaian, Jiangsu 223001, P.R. China
}

Received July 12, 2017; Accepted October 19, 2017

DOI: $10.3892 / \mathrm{mmr} .2018 .8633$

\begin{abstract}
The actions of thyroid hormone (TH) on lipid metabolism in the liver are associated with a number of genes involved in lipogenesis and lipid metabolism; however, the underlying mechanisms through which $\mathrm{TH}$ impacts on lipid metabolism remain to be elucidated. The present study aimed to investigate the effects of hyperthyroidism on the serum levels of the microRNA (miR) miR-206 and the role of miR-206 on TH-regulated lipid metabolism in liver cells. Serum was obtained from 12 patients diagnosed with hyperthyroidism and 10 healthy control subjects. Human hepatoblastoma (HepG2) cells were used to study the effects of triiodothyronine (T3) and miR-206 on lipid metabolism. Expression of miR-206 in serum and cells was determined by reverse transcription-quantitative polymerase chain reaction analysis. Lipid accumulation in HepG2 cells was assessed with Oil Red O staining. Suppression or overexpression of miR-206 was performed via transfection with a miR-206 mimic or miR-206 inhibitor. Serum miR-206 was significantly decreased in patients with hyperthyroidism compared with euthyroid controls. Treatment of HepG2 cells with T3 led to reduced total cholesterol (TC) and triglyceride (TG) content, accompanied by reduced miR-206 expression. Inhibition of
\end{abstract}

Correspondence to: Professor Xiaoyan Xu, Department of Pediatrics, Shu Yang Union Medical College Hospital, 3 Suzhou East Road, Suqian, Jiangsu 223600, P.R. China

E-mail: xiaoyu_alive@163.com

Professor Yaping Zhao, Department of Clinical Laboratory, The 82nd Hospital of Chinese People's Liberation Army, 100 Jiankang Road, Huaian, Jiangsu 223001, P.R. China

E-mail: xkh@njmu.edu.cn

${ }^{*}$ Contributed equally

Key words: microRNA-206, lipid metabolism, thyroid hormone, hyperthyroidism endogenous miR-206 expression decreased intracellular TG and TC content in HepG2 cells. By contrast, overexpression of miR-206 in HepG2 partially prevented the reduction in TG content induced by treatment with T3. In conclusion, serum miR-206 expression is reduced in patients with hyperthyroidism. In addition, miR-206 is involved in T3-mediated regulation of lipid metabolism in HepG2 cells, indicating a role for miR-206 in thyroid hormone-induced disorders of lipid metabolism in the liver.

\section{Introduction}

Hyperthyroidism is a pathological syndrome, characterized by high levels of circulating thyroid hormone (TH). Thyrotoxicosis is diagnosed by high serum concentrations of thyroxine (T4) and triiodothyronine (T3), and low serum concentrations of thyrotropin, additionally termed thyroid-stimulating hormone. Symptoms of overt hyperthyroidism include heat intolerance, palpitations, anxiety, fatigue, weight loss and muscle weakness, which are associated with lipid metabolism disorders (1). Accumulating evidence has demonstrated the important roles of $\mathrm{TH}$ in regulating lipid metabolism, with a number of genes involved in lipid metabolism in the liver, an important $\mathrm{TH}$ target tissue, being directly regulated by TH (2). The effects of TH on lipid metabolism in the liver are associated with a number of genes involved in lipogenesis and fatty acid oxidation (3). However, the underlying mechanisms associating $\mathrm{TH}$ with altered lipid metabolism remain to be elucidated.

MicroRNAs (miRNAs/miRs) are a class of small, noncoding, single-stranded RNA molecules containing 22-25 nucleotides, that are able to bind to the 3'untranslated region (3'UTR) of their target mRNA, leading to translational inhibition or mRNA degradation (4). miRNAs are important regulators of biological processes, including metabolism, cell growth, apoptosis and carcinogenesis $(5,6)$. Global miRNA and mRNA expression profiling has revealed a potential regulatory role for miRNAs in response to $\mathrm{TH}$ in the developing mouse liver (7). miR-1, miR-206, miR-133a and miR-133b expression was observed to be significantly increased in the livers of hypothyroid mice, while their expression was decreased in the livers 
of hyperthyroid mice (8). In addition, a number of miRNAs have been reported to be involved in cholesterol efflux and hepatic lipid metabolism (9). Therefore, miRNAs may serve a role in lipometabolism regulated by $\mathrm{TH}$ in hyperthyroidism.

The present study aimed to investigate the effects of increased TH on serum miR-206 expression in patients with hyperthyroidism. The role of the miRNA miR-206 in lipid metabolism was assessed in cultured human hepatoblastoma HepG2 cells in response to T3, with either overexpression or inhibition of endogenous miR-206 expression. It was hypothesized that miR-206 expression may be altered by $\mathrm{TH}$ and has an important role in T3-regulated lipid metabolism in liver cells.

\section{Materials and methods}

Patients. From October 2013 to March 2014 a total of 22 subjects recruited from October 2013 to March 2014 took part in the present study. A total of 12 patients diagnosed with hyperthyroidism were recruited from the Department of Endocrinology and 10 healthy subjects were recruited from the Physical Examination Center at The 82nd Hospital of Chinese People's Liberation Army (CPLA). Patients who had diabetes mellitus or other endocrine diseases, or with a body mass index $>30 \mathrm{~kg} / \mathrm{m}^{2}$, were excluded from taking part in the study. Patient details are shown in Table I. Patients taking any drugs known to influence TH metabolism were additionally excluded. The ethics committee of The 82nd Hospital of CPLA approved the present study. Written informed consent was obtained from all subjects.

Clinical characteristics analysis. The clinical characteristics of the study population include in serum free triiodothyronine (FT3), serum free thyroxine (FT4), alanine aminotransferase (ALT), aspartate aminotransferase (AST), triglyceride content (TG) and total cholesterol (TC). These were measured by Olympus AU640 automatic biochemical analyzer (Olympus Corporation, Tokyo, Japan).

Cell culture and treatment. Human hepatoblastoma (HepG2) cell line is known to be misidentified, originally thought to be a hepatocellular carcinoma cell line but shown to be from an hepatoblastoma (10). HepG2 is a perpetual cell line, which was derived from the liver tissue of a 15-year-old Caucasian American male with a well-differentiated hepatocellular carcinoma. HepG2 cells are a suitable in vitro model system for the study of polarized human hepatocytes. HepG2 cells and their derivatives are also used as a model system for studies of liver metabolism and toxicity of xenobiotics. HepG2 cells were cultured in Dulbecco's modified Eagle's medium (DMEM; Gibco; Thermo Fisher Scientific, Inc., Waltham, MA, USA) supplemented with $10 \%$ fetal bovine serum (Gibco; Thermo Fisher Scientific, Inc.), $100 \mathrm{U} / \mathrm{ml}$ penicillin, and $100 \mu \mathrm{g} / \mathrm{ml}$ streptomycin. For treatment with T3 (Sigma-Aldrich; Merck KGaA, Darmstadt, Germany), cells were seeded in 12-well culture plates at a density of $3 \times 10^{5}$ cells/well, and maintained for 2 days incubated at $37^{\circ} \mathrm{C}$ in a humidified chamber containing $5 \% \mathrm{CO}_{2}$. Following overnight incubation in serum-free DMEM, cells were treated with $100 \mathrm{nM}$ T3 for 12, 24 or 36 h. For the investigation of triglyceride synthesis, the medium was supplied with a $0.25 \mathrm{mM}$ free fatty acid (FFA) cocktail composed of lauric acid, myristic acid, linoleic acid, oleic acid and arachidonic acids (Sigma-Aldrich; Merck KGaA, Darmstadt, Germany).

Transient transfections. HepG2 cells, grown to 70-80\% confluence, were transiently transfected with miR-206 mimic (sense, 5'-UGGAAUGUAAGGAAGUGUGUGG-3' and antisense, 5'-ACACACUUCCUUACAUUCCAUU-3') or miR-206 inhibitor (5'-CCACACACUUCCUUACAUUCCA-3'), or a corresponding mimic negative control inhibitor (5'-UUCUCC GAACGUGUCACGUTT-3'; Shanghai GenePharma Co., Ltd., Shanghai, China), using Lipofectamine 2000 (Invitrogen; Thermo Fisher Scientific, Inc.), according to the manufacturer's protocol. All the mimic and inhibitor containing FAM reporter fluorophores were transfected at $10 \mathrm{nM}$. Transfection efficiency was observed using an inverted fluorescent microscope (original magnification, x400; Leica Microsystems $\mathrm{GmbH}$, Wetzlar, Germany), and evaluated using the reverse transcription-quantitative polymerase chain reaction (RT-qPCR). The mixtures were added to the culture, and the culture medium was changed after $8 \mathrm{~h}$, and cultured in DMEM supplemented with $10 \%$ fetal bovine serum for $36 \mathrm{~h}$ further for subsequent experiments.

$R T$-qPCR quantification of miR-206 expression. Cell/serum total RNA was extracted using TRIzol reagent (Invitrogen; Thermo Fisher Scientific, Inc.) or QIAzol reagent (Applied Biosystems; Thermo Fisher Scientific, Inc.), followed by isolation and purification using a miRNeasy Mini kit/miRNeasy serum kit (Applied Biosystems; Thermo Fisher Scientific, Inc.). Subsequently, first-strand cDNA was synthesized by RT using a TaqMan miRNA RT kit (Applied Biosystems; Thermo Fisher Scientific, Inc.). The expression of miR-206 was analyzed by qPCR using TaqMan Universal Master Mix II in the ABI 7500 Sequence Detection System (Applied Biosystems; Thermo Fisher Scientific, Inc.). All primers were provided in the TaqMan ${ }^{\circledR}$ MicroRNA Assays (cat. no. 4427975; Thermo Fisher Scientific, Inc.). PCR conditions were as follows: $50^{\circ} \mathrm{C}$ for $2 \mathrm{~min}, 95^{\circ} \mathrm{C}$ for $2 \mathrm{~min}$, and then 40 cycles of $94^{\circ} \mathrm{C}$ for $15 \mathrm{sec}$ and $60^{\circ} \mathrm{C}$ for $1 \mathrm{~min}$. U6 small nucleolar RNA was used as an internal standard for normalization. miR-206 expression was calculated using the comparative quantification cycle $(\mathrm{Cq})$ method $\left(2^{-\Delta \mathrm{Cq}} ; \Delta \mathrm{Cq}=\mathrm{Cq}_{\text {miR-206 }}-\mathrm{Cq}_{\mathrm{U} 6}\right)$, the $\mathrm{Cq}$ values were converted into RQ via the $2-\Delta \Delta \mathrm{Cq}$ method (11), incorporating the calculated amplification efficiency for each primer pair.

Oil Red o staining. Oil Red O stock solution was prepared in isopropanol $(0.25 \mathrm{~g} / 100 \mathrm{ml})$ and heated to $100^{\circ} \mathrm{C}$ for $10 \mathrm{~min}$. HepG2 cells grown to $70-80 \%$ confluence were washed with PBS and fixed using 4\% paraformaldehyde for $30 \mathrm{~min}$ at room temperature. Cells were soaked in filtered $0.6 \%(\mathrm{w} / \mathrm{v})$ Oil Red O solution (60\% Oil Red O stock solution, $40 \%$ water) for $20 \mathrm{~min}$ at room temperature. Cells were washed with water to remove unbound dye and visualized using light microscopy (original magnification, $\mathrm{x} 400$ ).

Statistical analysis. Each sample was analyzed in triplicate. All data are presented as the mean \pm standard error of the mean. Student's t-test was used to analyze the differences 
Table I. Clinical characteristics of study subjects.

\begin{tabular}{|c|c|c|c|c|}
\hline & $\begin{array}{c}\text { Patients with } \\
\text { hyperthyroidism }\end{array}$ & $\begin{array}{l}\text { Healthy } \\
\text { subjects }\end{array}$ & P-value & $\begin{array}{l}\text { P-value } \\
\text { summary }\end{array}$ \\
\hline No. subjects (female) & $12(8)$ & $10(8)$ & - & - \\
\hline Age, years & $49.0 \pm 7.5$ & $42.7 \pm 12.1$ & 0.1512 & ns \\
\hline FT3, pg/ml & $9.9 \pm 0.5$ & $3.5 \pm 0.1$ & $<0.0001$ & - \\
\hline FT4, ng/dl & $5.3 \pm 0.5$ & $1.3 \pm 0.0$ & $<0.0001$ & - \\
\hline ALT, U/1 & $23.8 \pm 1.9$ & $18.6 \pm 2.1$ & 0.0827 & ns \\
\hline $\mathrm{AST}, \mathrm{U} / \mathrm{l}$ & $25.3 \pm 1.7$ & $23.4 \pm 2.5$ & 0.5143 & ns \\
\hline $\mathrm{TG}, \mathrm{mmol} / \mathrm{l}$ & $1.22 \pm 0.31$ & $1.71 \pm 0.50$ & 0.3768 & ns \\
\hline $\mathrm{TC}, \mathrm{mmol} / \mathrm{l}$ & $3.31 \pm 0.25$ & $3.49 \pm 0.43$ & 0.7080 & ns \\
\hline
\end{tabular}

Data (mean \pm standard error of the mean) were compared using an unpaired t-test. FT3, serum free triiodothyronine; FT4, serum free thyroxine; ALT, alanine aminotransferase; AST, aspartate aminotransferase; TG, triglyceride content; TC, total cholesterol; ns, not significant.

between groups. The correlation between T4 parameters and miR-206 expression levels was analyzed using the Pearson product-moment correlation coefficient method. Comparisons among multiple groups were statistically performed using one-way analysis of variance followed by Dunnett's test. Two-tailed $\mathrm{P}<0.05$ was considered to indicate a statistically significant difference. The data were analyzed using SPSS software version 17.0 (SPSS, Inc., Chicago, IL, USA).

\section{Results}

Serum miR-206 levels in patients with hyperthyroidism. The clinical characteristics of the study population are presented in Table I. Patients with hyperthyroidism exhibited increased serum free T3 (FT3) and free T4 (FT4) concentrations compared with the control subjects.

The RT-qPCR analysis demonstrated that the serum miR-206 levels in patients with hyperthyroidism were significantly decreased compared with euthyroid control subjects (Fig. 1). The present study further analyzed the correlation between $\mathrm{TH}$ and miR-206 expression in patients with hyperthyroidism. No apparent correlation was observed between miR-206 expression and serum FT3 or FT4 levels (data not shown).

T3 downregulates miR-206 expression in HepG2 cells. In order to clarify the effect of TH on miR-206 expression, HepG2 cells were treated with $100 \mathrm{nM}$ T3 for 12,24 or $36 \mathrm{~h}$, with miR-206 expression examined using RT-qPCR analysis. The expression of miR-206 was significantly decreased $24 \mathrm{~h}$ subsequent to the treatment with T3, compared with HepG2 cells without T3 (Fig. 2). The expression of miR-206 remained reduced at $36 \mathrm{~h}$ following the addition of T3 (Fig. 2).

Effects of T3 on TG and TC synthesis in HepG2 cells. To validate the effects of T3 on lipid synthesis, HepG2 cells were cultured in DMEM supplemented with a 0.25 mM FFA cocktail and treated with $100 \mathrm{nM}$ T3 for 12, 24 or 36 h. Oil Red O staining demonstrated that T3 suppressed lipid accumulation in HepG2 cells (Fig. 3A). The TG was significantly reduced $12 \mathrm{~h}$ subsequent to treatment with T3 (Fig. 3B), while the TC

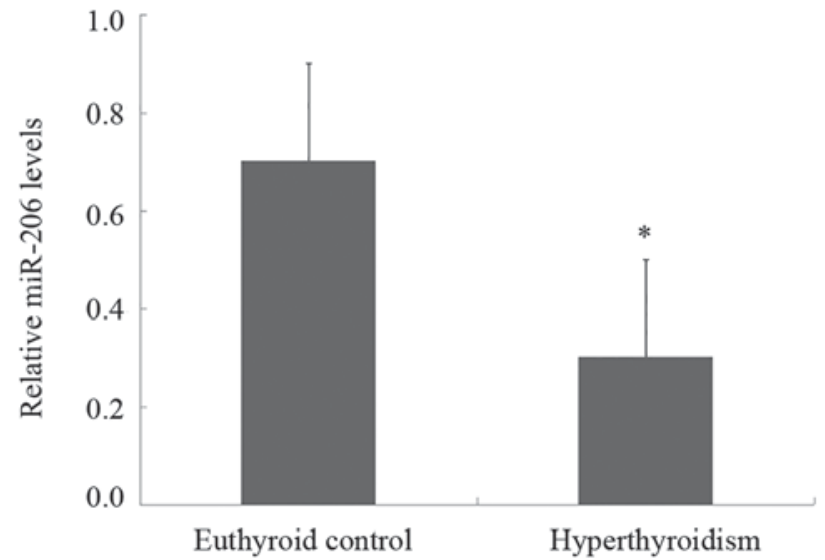

Figure 1. Serum miR-206 levels in patients with hyperthyroidism and euthyroid control subjects. Serum miR-206 levels were determined using reverse transcription-quantitative polymerase chain reaction analysis. The results are presented as the mean \pm standard error of the man. ${ }^{*} \mathrm{P}<0.05$ vs. euthyroid control. miR, microRNA.

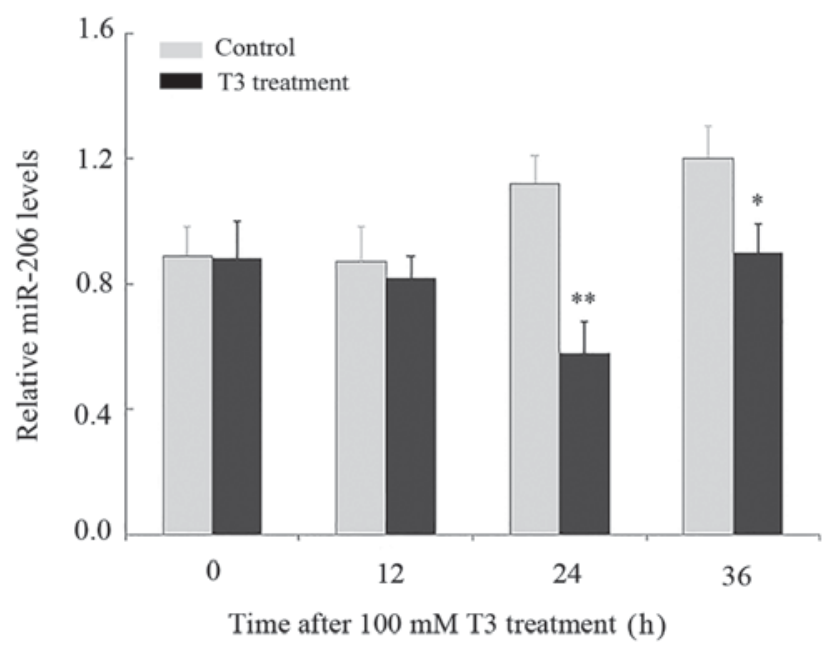

Figure 2. T3 downregulates miR-206 expression in HepG2 cells. HepG2 cells were treated with $100 \mathrm{nM}$ T3 for 12,24 , and $36 \mathrm{~h}$ ( $\mathrm{n}=4$ per group). The relative expression of miR-206 was analyzed using reverse transcription-quantitative polymerase chain reaction analysis. The data are presented as the mean \pm standard deviation. ${ }^{*} \mathrm{P}<0.05,{ }^{* *} \mathrm{P}<0.01$ vs. respective control. T3, triiodothyronine; miR, microRNA. 
A
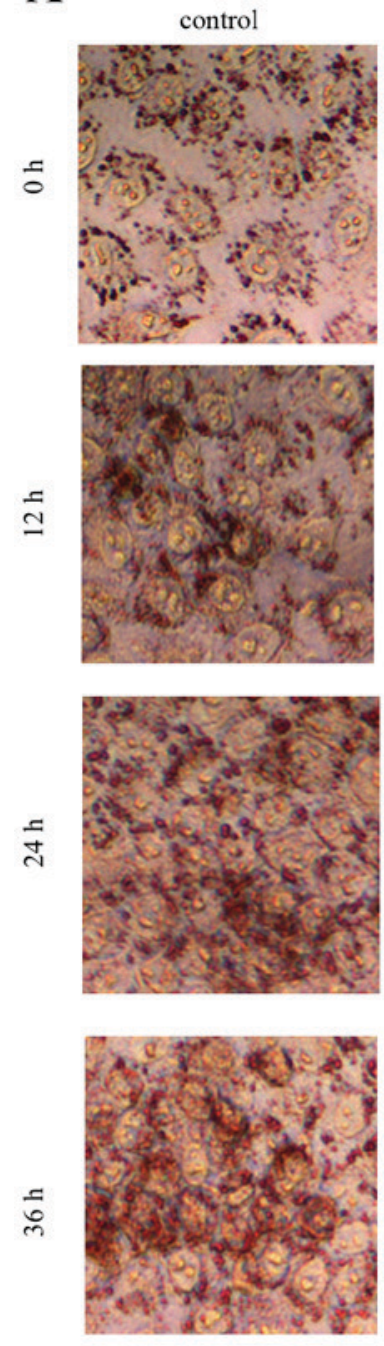

T3 treatment
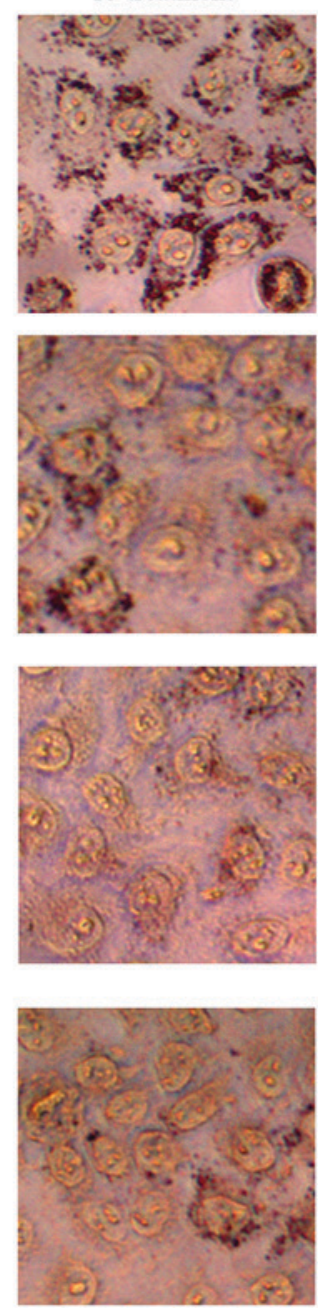

B

B Control

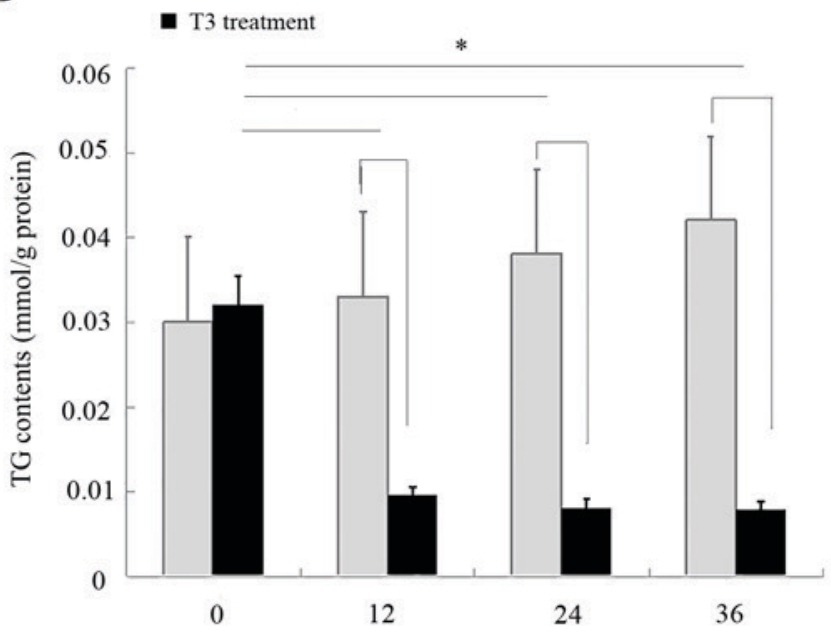

Time after treatment with $100 \mathrm{mM} \mathrm{T3}$ (h)

C

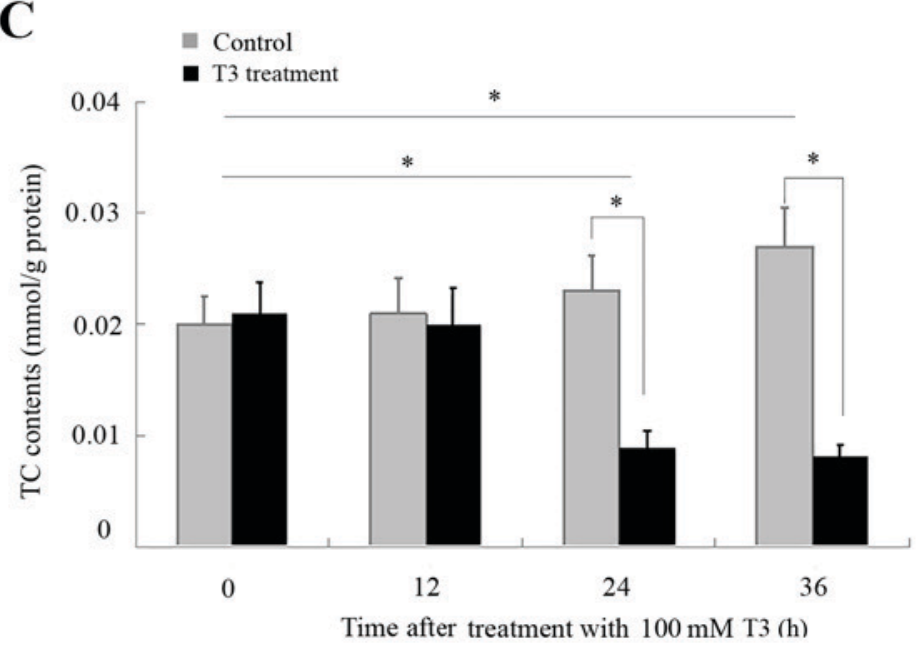

Figure 3. Effects of T3 on TG synthesis in HepG2 cells. HepG2 cells were cultured in Dulbecco's modified Eagle's medium supplemented with 0.25 mM free fatty acid cocktail and treated with $100 \mathrm{nM}$ T3 for 12, 24 and $36 \mathrm{~h}$ ( $\mathrm{n}=4$ per group). (A) TG composition was visualized using Oil Red O staining (original magnification, $\mathrm{x} 400$ ). (B) The TG of the cells was determined enzymatically using glycerol-3-phosphate oxidase-PAP. (C) The TC content of the cells was determined enzymatically using cholesterol oxidase-PAP. Data are presented as the mean \pm standard deviation. ${ }^{*} \mathrm{P}<0.05$. TG, triglyceride content; TC, total cholesterol; PAP, phenol + aminophenazone; T3, triiodothyronine.

content was significantly reduced $24 \mathrm{~h}$ subsequent to treatment with T3 (Fig. 3C). The TG and TC content of the HepG2 cells remained reduced $36 \mathrm{~h}$ following treatment with $\mathrm{T} 3$.

Effects of miR-206 on TG and TC composition in HepG2 cells. The transfection of HepG2 cells with miR-206 inhibitor confirmed that the inhibitor effectively knocked down miR-206 expression (Fig. 4A). The addition of the miR-206 inhibitor reduced the TG at $24 \mathrm{~h}$, and $\mathrm{TG}$ and $\mathrm{TC}$ content at $36 \mathrm{~h}$ in HepG2 cells (Fig. 4B).

$m i R-206$ partially rescues the TG reduction induced by treatment with T3 in HepG2 cells. The transfection of HepG2 cells with the miR-206 mimic or mimic negative control confirmed that the miR-206 mimic increased miR-206 expression (Fig. 5A). HepG2 cells treated with T3 exhibited a reduced TG content that was restored with miR-206 overexpression (Fig. 5B). The addition of mimic negative control did not alter TG in T3-treated cells.

\section{Discussion}

Appropriate TH levels are important for normal growth, development and metabolism in adults (12). It is well established that $\mathrm{TH}$ status is associated with body weight and energy expenditure (13). Hyperthyroidism, excess TH, promotes a hypermetabolic state characterized by increased resting energy expenditure and weight loss. Serum TG and TC are typically decreased in patients with hyperthyroidism. TH exerts direct and indirect actions on the regulation of TG and TC production, disposal and efflux $(12,14,15)$, primarily through specific nuclear receptor-mediated T3 actions that modulate gene transcription. However, accumulating evidence has indicated that non-genomic mechanisms may be involved in the $\mathrm{TH}$ regulation of metabolism (16-18). Reports have indicated that miRNAs have a potential role in mediating the action of TH $(7,19)$. The results of the present study demonstrated that miR-206 expression was significantly decreased in patients with hyperthyroidism compared with 

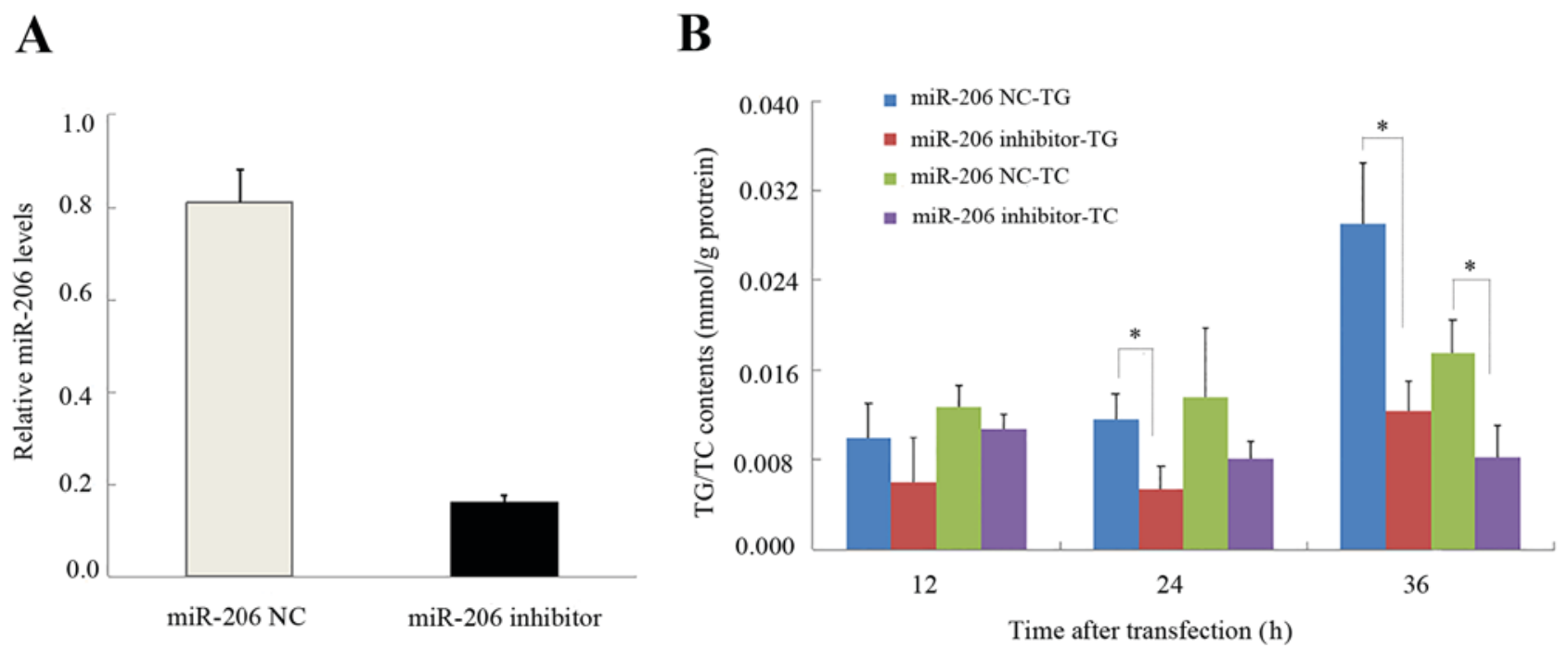

Figure 4. Effects of miR-206 on TG and TC composition in HepG2 cells. (A) HepG2 cells were transfected with miR-206 inhibitor to induce knockdown of miR-206 expression. (B) TG and TC concentration was determined at 12, 24 and $36 \mathrm{~h}$ post-transfection ( $\mathrm{n}=4$ per group). ${ }^{*} \mathrm{P}<0.05$. miR, microRNA; NC, negative control; TG, triglyceride content; TC, total cholesterol.

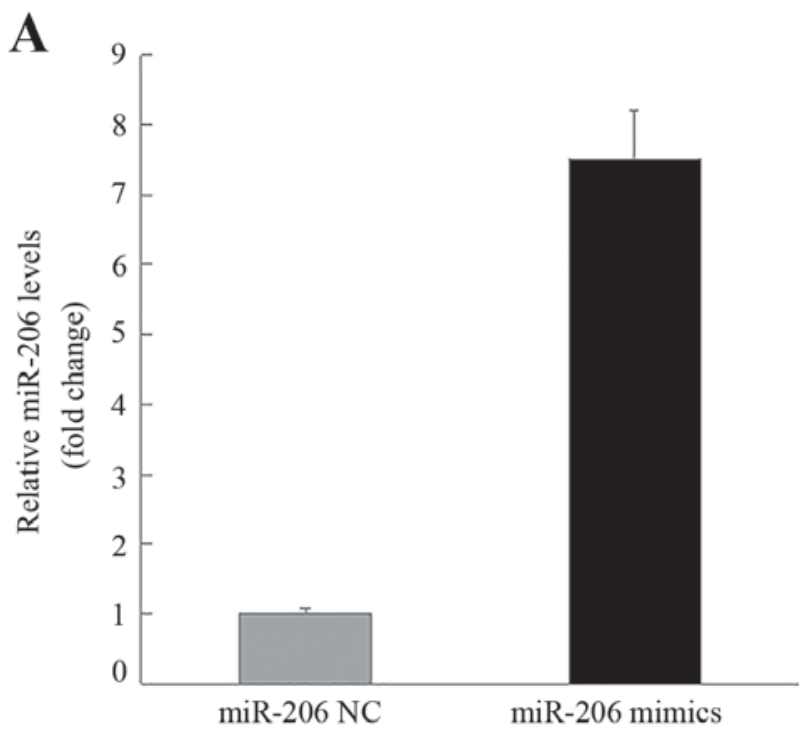

Figure 5. miR-206 partially restores T3-induced reductions in TG. (A) HepG2 cells transfected with miR-206 mimic or mimic NC were treated with T3. (B) TG was determined enzymatically using glycerol-3-phosphate oxidase/phenol+aminophenazone. ${ }^{*} \mathrm{P}<0.05$; ${ }^{* *} \mathrm{P}<0.005$. TG, triglyceride content; miR, microRNA; NC, negative control. T3, triiodothyronine.

euthyroid subjects. Therefore, understanding the association between TH and miR-206 may further the understanding of the mechanisms underlying metabolic dysfunction in patients with hyperthyroidism.

The liver is an important target of TH in the regulation of energy metabolism and physiology $(20,21)$. Hyperthyroidism frequently results in liver dysfunction, and hypothyroidism is associated with non-alcoholic fatty liver disease. Previous studies have suggested that T3 has the ability to reduce levels of lipids, including TC and TG $(22,23)$. The results of the present study demonstrated that prolonged treatment with $\mathrm{T} 3$ led to reduced $\mathrm{TG}$ and $\mathrm{TC}$ content in HepG2 cells. In addition, it was observed that that treatment with T3 resulted in a downregulation of miR-206 expression. Increasing evidence has suggested that miRNAs are
B

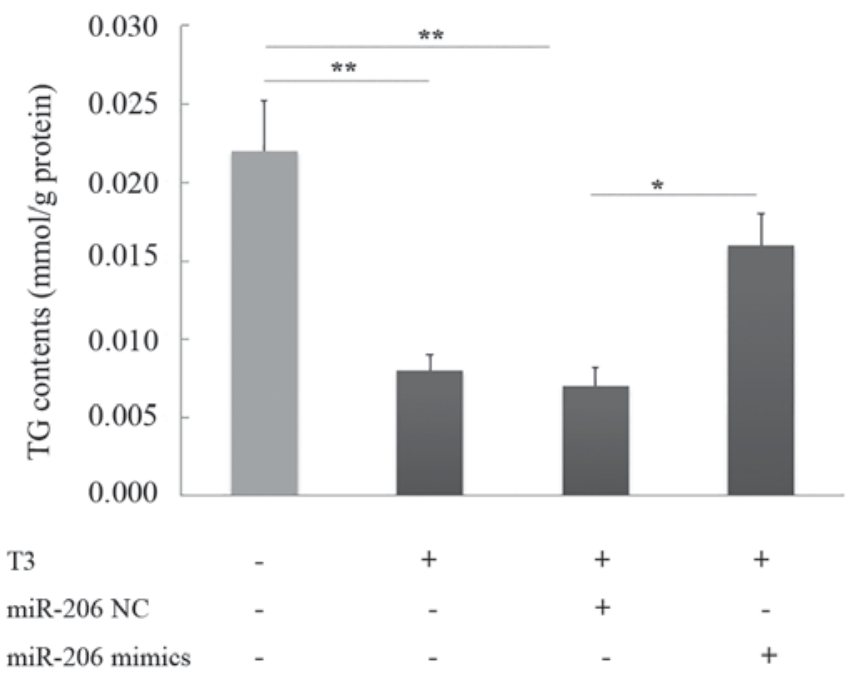

involved in the post-transcriptional regulation of genes in lipid metabolism $(24,25)$. Previous studies have indicated that the regulatory role of miR-206 in TC handling is tissue-specific $(26,27)$. It was demonstrated in the present study that the inhibition of endogenous miR-206 expression in HepG2 cells resulted in decreased intracellular TG and TC content. These results indicated that miR-206 may be involved in the TH-mediated regulation of lipid metabolism in HepG2 cells.

In order to confirm that miR-206 has a role in the TH-mediated regulation of lipid metabolism, HepG2 cells were transfected with an miR-206 mimic prior to being treated with T3. Overexpression of miR-206 in HepG2 cells increased lipid accumulation and attenuated the T3-induced downregulation of TG. A previous study demonstrated that 
expression of miR-206 increased in the liver of hypothyroid mice compared with controls (7). Given that TH deficiency is associated with an increased incidence of hepatic steatosis, these results suggested that miR-206 may serve an important role in the lipid dysregulation in the liver associated with hyperthyroidism and hypothyroidism.

The present study has limitations, in that the miR-206 levels were only determined in the serum of hyperthyroid patients and not in the liver. In addition, the use of HepG2 cells provided an in vitro model of lipid metabolism in liver cells and conclusions may not be directly applied to in vivo liver physiology. However, the results of the present study suggested that miRNAs may be a promising target for future investigations into disorders of lipid metabolism in the liver in cases of hyper- or hypothyroidism. Future studies, including the use of mouse models of hyperthyroidism, are required for in vivo investigation into the effects of miR-206 on lipid metabolism in the liver in a physiological context. Further larger studies may be used to study the effects of hyper- or hypothyroidism on miR-206 expression in human subjects.

In conclusion, the results of the present study demonstrated that patients with hyperthyroidism exhibited decreased serum miR-206 expression levels and that miR-206 was involved in the T3-mediated regulation of lipid metabolism in HepG2 cells. The results of the present study provided novel insights into the molecular mechanisms underlying $\mathrm{TH}$ regulation of lipid metabolism. Whether miR-206 is affected in the liver in patients with hyperthyroidism remains to be elucidated. Further experiments are required to clarify whether miR-206 has the potential to be either a biomarker or therapeutic target in hyperthyroidism.

\section{Acknowledgements}

Not applicable.

\section{Funding}

The present study was supported by a grant from the Medical and Scientific Innovations Project of Chinese People's Liberation Army (grant no. 14SM030).

\section{Availability of data and materials}

The analyzed data sets generated during the study are available from the corresponding author on reasonable request.

\section{Authors' contributions}

YJZ, HW and YG collected data. YJZ, CZ and NZ conducted the experiments. YJZ, NZ, WK, RL, and XX analysed the data. CZ and YPZ wrote the paper. YPZ and XX designed the study.

\section{Ethics approval and consent to participate}

The Ethics Committee of the 82nd Hospital of CPLA approved the present study. Written informed consent was obtained from all subjects.

\section{Consent for publication}

Written informed consent was obtained from all subjects.

\section{Competing interests}

All authors declared that they have no conflict of interest with regard to this work.

\section{References}

1. Cooper D: Hyperthyroidism. Lancet 362: 459-468, 2003.

2. Boelaert K and Franklyn JA: Thyroid hormone in health and disease. J Endocrinol 187: 1-15, 2005.

3. Oppenheimer JH, Schwartz HL, Lane JT and Thompson MP: Functional relationship of thyroid hormone-induced lipogenesis, lipolysis and thermogenesis in rat. J Clin Invest 87: 125-132, 1991.

4. Kong YW, Cannell IG, de Moor CH, Hill K, Garside PG, Hamilton TL, Meijer HA, Dobbyn HC, Stoneley M, Spriggs KA, et al: The mechanism of micro-rna-mediated translation repression is determined by the promoter of the target gene. Proc Nail Acad Sci USA 105: 8866-8871, 2008.

5. Chen XM: MicroRNA signatures in liver diseases. World J Gastroentero 15: 1665-1672, 2009.

6. Lynn FC: Meta-regulation: microRNA regulation of glucose and lipid metabolism. Trends Endocrinol Metab 20: 452-459, 2009.

7. Dong H, Paquette M, Williams A, Zoeller RT, Wade M and Yauk C: Thyroid hormone may regulate mRNA abundance in liver by acting on micrornas. PLoS One 5: e12136, 2010.

8. Visser WE, Heemstra KA, Swagemakers SM, Ozgür Z, Corssmit EP, Burggraaf J, vanIjcken WF, vanderSpek PJ, Smit JW and Visser TJ: Physiological thyroid hormone levels regulate numerous skeletal muscle transcripts. J Clin Endocr Metab 94: 3487-3496, 2009.

9. Moore KJ, Rayner KJ, Suárez Y and Fernández-Hernando C: The role of microRNAs in cholesterol efflux and hepatic lipid metabolism. Annu Rev Nutr 31: 49-63, 2011.

10. López-Terrada D, Cheung SW, Finegold MJ and Knowles BB: Hep g2 is a hepatoblastoma-derived cell line. Hum Pathol 40: 1512-1515, 2009.

11. Livak KJ and Schmittgen TD: Analysis of relative gene expression data using real-time quantitative PCR and the 2(-Delta Delta C(T)) method. Methods 25: 402-408, 2001.

12. Brent GA: Mechanisms of thyroid hormone action. J Clin Invest 122: 3035-3043, 2012.

13. Iwen KA, Schröder E and Brabant G: Thyroid hormones and the metabolic syndrome. Eur Thyroid J 2: 83-92, 2013.

14. Webb P: Thyroid hormone receptor and lipid regulation. Curr Opin Invest Drugs 11: 1135-1142, 2010.

15. Shoemaker TJ, Kono T, Mariash $\mathrm{CN}$ and Evansmolina C: Thyroid hormone analogues for the treatment of metabolic disorders: New potential for unmet clinical needs? Endocr Pract 18: 954-964, 2012.

16. Cheng SY, Leonard JL and Davis PJ: Molecular aspects of thyroid hormone actions. Endocr Rev 31: 139-170, 2010.

17. Cordeiro A, deSouza LL, Oliveira LS, Faustino LC, Santiago LA, Bloise FF, Ortiga-Carvalho TM, Almeida NA and Pazos-Moura CC: Thyroid hormone regulation of Sirtuin 1 expression and implications to integrated responses in fasted mice. J Endocrinol 216: 181-193, 2013.

18. Sinha RA, You SH, Zhou J, Siddique MM, Bay BH, Zhu X, Privalsky ML, Cheng SY, Stevens RD, Summers SA, et al: Thyroid hormone stimulates hepatic lipid catabolism via activation of autophagy. J Clin Invest 122: 2428-2438, 2012.

19. Yap CS, Sinha RA, Ota S, Katsuki M and Yen PM: Thyroid hormone negatively regulates CDX2 and SOAT2 mRNA expression via induction of miRNA-181d in hepatic cells. Biochen Bioph Res Commun 440: 635-639, 2013.

20. Ståhlberg N, Merino R, Hernández LH, Fernández-Pérez L, Sandelin A, Engström P, Tollet-Egnell P, Lenhard B and Flores-Morales A: Exploring hepatic hormone actions using a compilation of gene expression profiles. BMC Physiol 5: 8, 2005. 
21. Dong H, Yauk CL, Williams A, Lee A, Douglas GR and Wade MG: Hepatic gene expression changes in hypothyroid juvenile mice: Characterization of a novel negative thyroid-responsive element. Endocrinology 148: 3932-3940, 2007.

22. Shibata A, Kawakami Y, Kimura T, Miyazawa $T$ and Nakagawa K: $\alpha$-tocopherol attenuates the triglyceride- and cholesterol-lowering effects of rice bran tocotrienol in rats fed a western diet. J Agr Food Chem 64: 5361-5366, 2016.

23. Goldberg IJ, Huang LS, Huggins LA, Yu S, Nagareddy PR, Scanlan TS and Ehrenkranz JR: Thyroid hormone reduces cholesterol via a non-LDL receptor-mediated pathway. Endocrinology 153: 5143-5149, 2012.

24. Vickers KC, Sethupathy P, Baran-Gale J and Remaley AT: Complexity of microRNA function and the role of isomiRs in lipid homeostasis. J Lipid Res 54: 1182-1191, 2013.

25. Vickers KC, Shoucri BM, Levin MG, Wu H, Pearson DS, Osei-Hwedieh D, Collins FS, Remaley AT and Sethupathy P: MicroRNA-27b is a regulatory hub in lipid metabolism and is altered in dyslipidemia. Hepatology 57: 533-542, 2013.
26. Zhong D, Huang G, Zhang Y, Zeng Y, Xu Z, Zhao Y, He X and He F: MicroRNA-1 and microRNA-206 suppress LXR $\alpha$-induced lipogenesis in hepatocytes. Cell Signal 25: 1429-1437, 2013.

27. Vinod M, Chennamsetty I, Colin S, Belloy L, De Paoli F, Schaider H, Graier WF, Frank S, Kratky D, Staels B, et al: MIR-206 controls LXR $\alpha$ expression and promotes LXR-mediated cholesterol efflux in macrophages. Biochim Biophys Acta 1841: 827-835, 2014.

(i) () $९$ This work is licensed under a Creative Commons Attribution-NonCommercial-NoDerivatives 4.0 International (CC BY-NC-ND 4.0) License. 